\title{
Article \\ Effects of El Niño/La Niña on the Number of Imported Shigellosis Cases in the Republic of Korea, 2004-2017
}

\author{
Jong-Hun Kim ${ }^{1}\left(\mathbb{D}\right.$, Jisun Sung ${ }^{1}$, Ho-Jang Kwon ${ }^{2}$ and Hae-Kwan Cheong ${ }^{1, * \mathbb{C}}$ \\ 1 Department of Social and Preventive Medicine, Sungkyunkwan University School of Medicine, \\ Suwon 16419, Korea; kimjh32@skku.edu (J.-H.K.); vivid82th@hanmail.net (J.S.) \\ 2 Department of Preventive Medicine, Dankook University College of Medicine, Cheonan 31116, Korea; \\ hojangkwon@gmail.com \\ * Correspondence: hkcheong@skku.edu; Tel.: +82-31-299-6300
}

Citation: Kim, J.-H.; Sung, J.; Kwon, H.-J.; Cheong, H.-K. Effects of El Niño/La Niña on the Number of Imported Shigellosis Cases in the Republic of Korea, 2004-2017. Int. J. Environ. Res. Public Health 2021, 18, 211. https://doi.org/10.3390/ ijerph18010211

Received: 29 October 2020 Accepted: 25 December 2020 Published: 30 December 2020

Publisher's Note: MDPI stays neutral with regard to jurisdictional clai$\mathrm{ms}$ in published maps and institutional affiliations.

Copyright: (C) 2020 by the authors. Licensee MDPI, Basel, Switzerland. This article is an open access article distributed under the terms and conditions of the Creative Commons Attribution (CC BY) license (https:// creativecommons.org/licenses/by/ $4.0 /)$.

\begin{abstract}
Shigellosis is a major diarrheal disease in low- and middle-income countries. Although the incidence of such diseases in South and Southeast Asia has been associated with climate fluctuations linked to the El Niño-Southern Oscillation (ENSO), the impact of ENSO on shigellosis infections remains unknown. Data reported to being infected with shigellosis while traveling abroad from 2004 to 2017 were obtained from the Korea Centers for Disease Control and Prevention. We investigated the relationship between the Oceanic Niño Index (ONI) and Indian Ocean Dipole Mode Index and the relative risk of shigellosis in outbound travelers using distributed lag linear and non-linear models. From 2004 to 2017, 87.1\% of imported shigellosis was infected in South and Southeast Asian countries. The relative risk of imported shigellosis infection in outbound travelers increased as the ONI decreased. In the association with the five-month cumulative ONI, the relative risk of infection continuously increased as the La Niña index gained strength. Climate fluctuations associated with the La Niña phenomenon in South and Southeast Asian countries can lead to issues in sanitation and water safety. Our findings suggest that the decreasing trend in the ONI is associated with an increased incidence of shigellosis in these countries.
\end{abstract}

Keywords: shigellosis; bacterial dysentery; South Korea; Republic of Korea; El Niño; La Niña; ENSO; IOD; Southeast Asia

\section{Introduction}

Shigellosis is a clinical syndrome with symptoms such as nausea, vomiting, diarrhea, and abdominal cramps caused by the Shigella species invading intestinal epithelial cells $[1,2]$. Shigella is an important etiologic agent of travelers' diarrhea and is only carried by humans and upper primates [3]. It is mainly transmitted between people through the fecal-oral route and also through the intake of contaminated food or water. According to research conducted in South and Southeast Asian countries, the annual incidence of shigellosis from 2000 to 2004 for all ages was 0.6-7.9 cases per 1000 residents [4]. Shigella has been reported to account for $2.2 \%$ to $8.0 \%$ of travelers' diarrhea cases in South and Southeast Asian countries [5,6].

Diarrheal diseases, including shigellosis, are well known as climate-sensitive diseases; their incidence usually increases with the occurrence of drought or floods. This is related to poor hygiene, sanitation, and a lack of clean drinking water. Weather events such as droughts or floods in South and Southeast Asian countries are affected by the El Niño Southern Oscillation (ENSO) phenomenon, which refers to variations in climate conditions resulting from the interaction of sea surface temperatures and atmospheric pressure in the tropical Pacific $[7,8]$. El Niño, commonly called "warm event," and La Niña, called "cool event," are parts of the ENSO cycle that last 12-18 months over a period of 2-7 years and the impact of which depends on geographical characteristics. Many studies have demonstrated the association between the ENSO and diarrheal diseases, particularly 
cholera [9-12]. A few studies have investigated the link between shigellosis and ENSO. A study conducted in Bangladesh showed that the pattern of shigellosis outbreaks was associated with the monsoon floods in a manner similar to that of cholera, and the floods were related to ENSO activity from the preceding winter [13]. A Chinese study that assessed the impact of the ENSO on shigellosis reported a negative association between the number of monthly shigellosis cases and monthly Southern Oscillation Index, which is an index of the ENSO [14]. A significant association between La Niña-related floods and an increased risk of shigellosis infection has also been reported in Peru [15]. Although studies have reported the relationship between the incidence of shigellosis in individual countries and climate indices, reviews from South and Southeast Asian regions have been insufficient. This study aimed to investigate the impact of the ENSO on imported shigellosis cases among South Koreans who had traveled to South and Southeast Asian countries.

\section{Materials and Methods}

\subsection{Data Sources: Shigellosis Cases and Outbound Travellers}

We analyzed the relationship between the number of imported shigellosis cases from South and Southeast Asian countries and sea surface temperature indices as climate indices after adjusting for the number of outbound South Korean travelers, seasonality, and longterm time trends. In South Korea, shigellosis is designated as a notifiable infectious disease that must be reported to the national infectious disease reporting system within $24 \mathrm{~h}$. Legal infectious diseases are reported by both the doctor who diagnosed them and the institutions that confirmed the pathogens of infectious diseases. Once a case of notifiable infectious disease is reported, a detailed epidemiological investigation is conducted by health authorities on the risk factors at the time of infection. The epidemiologic surveillance data of patients with shigellosis were obtained from the Korea Centers for Disease Control \& Prevention (KCDC). Among outbound travelers, we included only those individuals with shigellosis infections acquired after traveling to South and Southeast Asian countries (South Asian countries: India, Nepal, Bangladesh, Pakistan; Southeast Asian Countries: Cambodia, Philippines, Vietnam, Thailand, Indonesia, Laos, Myanmar, Malaysia, Singapore). The monthly statistical data of overseas South Korean tourists provided by the Korea Tourism Organization were used to determine the number of outbound travelers [16].

\subsection{Data Sources: Climate Indices}

For the tropical Pacific and Indian Oceans, there are modes of internal fluctuations leading to climate fluctuations, namely, the ENSO and the Indian Ocean Dipole (IOD), respectively. The ENSO is a climatic event in the Pacific that has a wide impact on the world's climate and is particularly associated with droughts and floods. Meanwhile, IOD is associated with sea-level temperature fluctuations in the Indian Ocean as well as droughts and abnormal rainfall in Southeast Asia and the eastern African region. We included the dipole mode event in Indian Ocean as an independent variable because it is independent of the ENSO in the Pacific. The Oceanic Niño Index (ONI) is a major index used to monitor the ENSO. The ONI is calculated by a three-month time averaging of the sea surface temperature anomalies in an area of the east-central equatorial Pacific Ocean called the Nino 3.4 region ( $5 \mathrm{~S}$ to $5 \mathrm{~N}$; $170 \mathrm{~W}$ to $120 \mathrm{~W}$ ). Just as ENSO-related climatic fluctuations are presented using ONI indicators, the Indian Ocean Dipole Mode Index (DMI) is used to present the IOD-related climatic fluctuations. DMI is an indicator of sustained changes in the difference between sea surface temperatures of the tropical western $\left(50^{\circ} \mathrm{E}\right.$ to $70^{\circ} \mathrm{E}$, $10^{\circ} \mathrm{S}$ to $\left.10^{\circ} \mathrm{N}\right)$ and eastern $\left(90^{\circ} \mathrm{E}\right.$ to $110^{\circ} \mathrm{E}, 10^{\circ} \mathrm{S}$ to the equator) Indian Ocean. We used monthly data on the ONI and DMI provided by the Asia-Pacific Economic Cooperation (APEC) climate center [17].

\subsection{Data Analysis}

After identifying trends in domestic and imported cases of shigellosis reported in South Korea from 2004 to 2017, we classified imported cases by the countries where 
transmission of the infection was estimated to have occurred. The country in which the transmission of such shigellosis infection is estimated to have occurred was based on the records of the epidemiological investigation. In this study, distributed lag nonlinear models (DLNM) and Poisson regression models were used to analyze non-linear exposure-response relationships while considering the lag-time effects of climate indices for imported shigellosis cases $[18,19]$. The dependent variable is the number of monthly shigellosis patients reported to be infected during travel to South and Southeast Asia, and the independent variable was the monthly ONI. The monthly number of overseas travelers, monthly DMI, seasonality, and long-term time trends were the variables adjusted in the models. As the occurrence of El Niño is based on the ONI, we attempted to interpret the results based on this index. Analyses were performed using the R package "dlnm".

$$
\begin{gathered}
Y_{t}=\text { Quasi }-\operatorname{poisson}\left(Y_{t}\right), t=1, \ldots \ldots, n \\
\log \left(Y_{t}\right)=\alpha+\sum_{l=1}^{L} \beta_{0}\left(O N I_{t, l}\right)+\sum_{l=1}^{L} \beta_{1}\left(D M I_{t, l}\right)+\beta_{2} \times n s\left(\text { season }, \lambda_{1}\right) \\
+\beta_{3} \times n s\left(\text { time }, \lambda_{2}\right)+\beta_{4} \times \log \left(N_{t}\right)
\end{gathered}
$$

where $t$ is the month reported to the KCDC; $Y_{t}$ is the monthly imported number of shigellosis cases for month $t ; \alpha$ is the intercept; $O N I_{t, l}\left(D M I_{t, l}\right)$ is the matrix obtained by applying the DLNM to the ONI(DMI); $l$ is the lag month; $L$ is the maximum lag; $N_{t}$ is an offset to control for the number of outbound travelers; $n s\left(\right.$ season, $\left.\lambda_{1}\right)$ is the natural cubic spline smoothing function of the 'season' variable for the control of seasonal patterns; ns(time, $\lambda_{2}$ ) is the natural cubic spline smoothing function of the 'time' variable for the control of long-term time trends and fluctuations; $\beta_{0}, \beta_{1}, \beta_{2}, \beta_{3}$, and $\beta_{4}$ are the coefficients for $O N I_{t, l}$, $D M I_{t, l}, n s($ season,$\lambda)$, and $\log \left(N_{t}\right)$, respectively. We used a natural cubic spline basis with three degrees of freedom (df) for the ONI and two df for the lag. A natural cubic spline with $3 \mathrm{df}$ was used for both the DMI and the lag. To control seasonal patterns and long-term time trends, natural cubic splines with $3 \mathrm{df}$ and $7 \mathrm{df}$ were used, respectively. To choose the best model with optimal df, we adopted the smaller Akaike Information Criterion (AIC) value for the quasi-Poisson model and conducted a sensitivity analysis (Table S1).

\subsection{Ethical Statement}

This study was approved by the institutional review board of Dankook University (IRB No. DKUH 2018-09-011).

\section{Results}

The overall number of shigellosis cases reported in South Korea tended to decrease from 2004 to 2017 (Figure 1). The total number of cases, which occurred close to 500 cases in 2004, has decreased significantly since 2014 and is reported to be less than 120 cases. In the classification by country suspected of being infected, we observed a gradual decrease in the proportion of domestic cases, while the proportion of cases imported from abroad increased progressively. From 2004 to 2017, a total of 698 imported shigellosis cases were reported to the KCDC (Table 1). When assessing the overseas regions suspected of originating imported infections, 476 cases $(68.2 \%)$ were estimated as being infected with shigellosis while traveling in Southeast Asian countries. The next frequent regions were; 132 cases (18.9\%) in South Asian countries, 63 cases (9.0\%) in East Asian countries, and 27 cases $(3.8 \%)$ in other regions. More specifically, in Southeast Asian countries, 137 cases (19.6\%) were reported among those who travelled to Cambodia, followed by the Philippines with 119 cases $(17.0 \%)$ and Vietnam with 89 cases (12.8\%). A total of 132 cases were reported by travelers who visited South Asian countries, with 124 cases (17.8\%) being infected during travel to India, accounting for most cases. In East Asia, it was the largest in China, with 48 cases (6.9\%). From 2004 to 2017, a total of four El Niño and five La Niña events occurred (El Niño: June 2004-May 2005, August 2006-January 2007, June 2009-April 2010, and March 2015-May 2016; La Niña: September 2007-May 2008, July 2010-April 2011, 
August 2011-March 2012, August 2016-January 2017, and September 2017-December 2017) (Figure 2).

Table 1. Distribution of imported cases of shigellosis across travel destinations, 2004-2017.

\begin{tabular}{cccc}
\hline Region & Country & Cases & $\%$ \\
\hline Total & & 698 & $100.0 \%$ \\
Southeast Asia & Subtotal & 476 & $68.2 \%$ \\
& Cambodia & 137 & $19.6 \%$ \\
& Philippines & 119 & $17.0 \%$ \\
& Vietnam & 89 & $12.8 \%$ \\
& Thailand & 52 & $7.4 \%$ \\
& Indonesia & 46 & $6.6 \%$ \\
& Laos & 19 & $2.7 \%$ \\
& Myanmar & 5 & $0.7 \%$ \\
South Asia & Malaysia & 3 & $0.4 \%$ \\
& Singapore & 3 & $0.4 \%$ \\
& Others & 3 & $0.4 \%$ \\
& Subtotal & 132 & $18.9 \%$ \\
& India & 124 & $17.8 \%$ \\
& Nepal & 3 & $0.4 \%$ \\
East Asia & Bangladesh & 3 & $0.4 \%$ \\
& Others & 2 & $0.3 \%$ \\
& Subtotal & 63 & $9.0 \%$ \\
China & 48 & $6.9 \%$ \\
Americas & Mongolia & 11 & $1.6 \%$ \\
Eceania & Japan & 3 & $0.4 \%$ \\
Unknown & Others & 1 & $0.1 \%$ \\
West Asia & & 2 & $0.3 \%$ \\
& & 12 & $1.7 \%$ \\
& & 2 & $0.3 \%$ \\
& & 1 & $0.1 \%$ \\
& & & $0.1 \%$ \\
\hline & & &
\end{tabular}

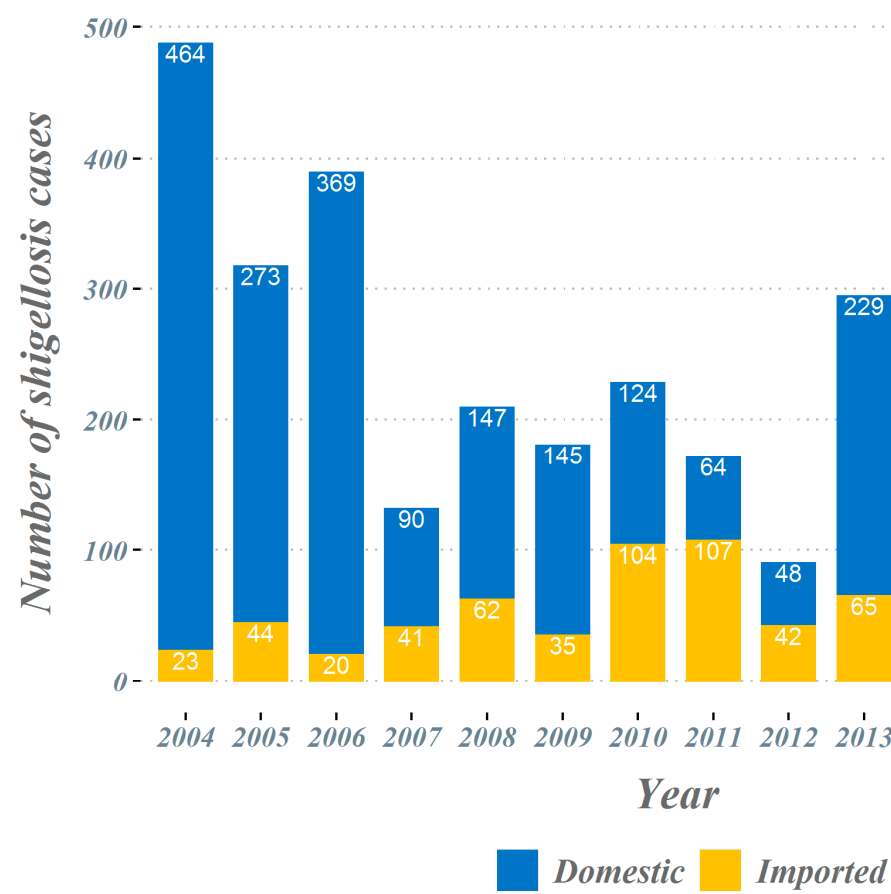

Figure 1. Shigellosis in the Republic of Korea, 2004-2017. 


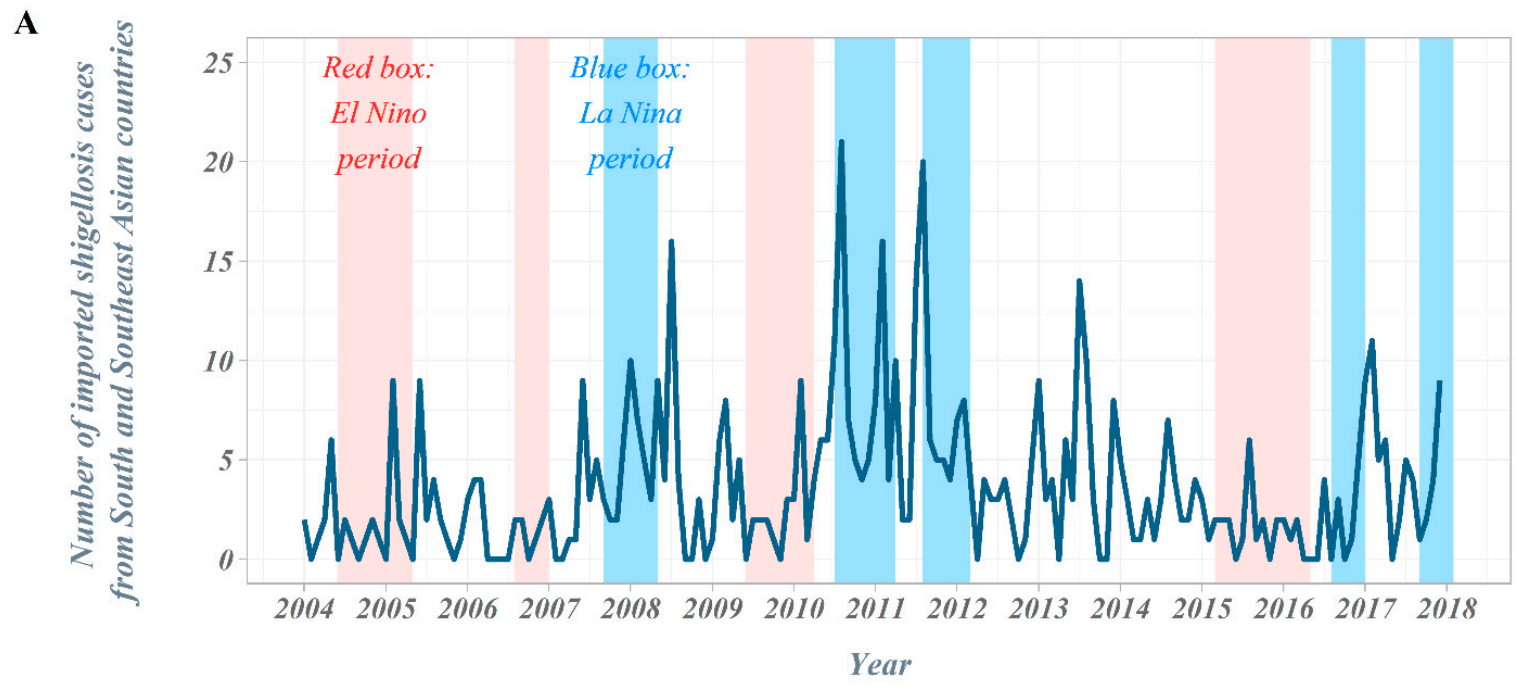

$\mathbf{B}$

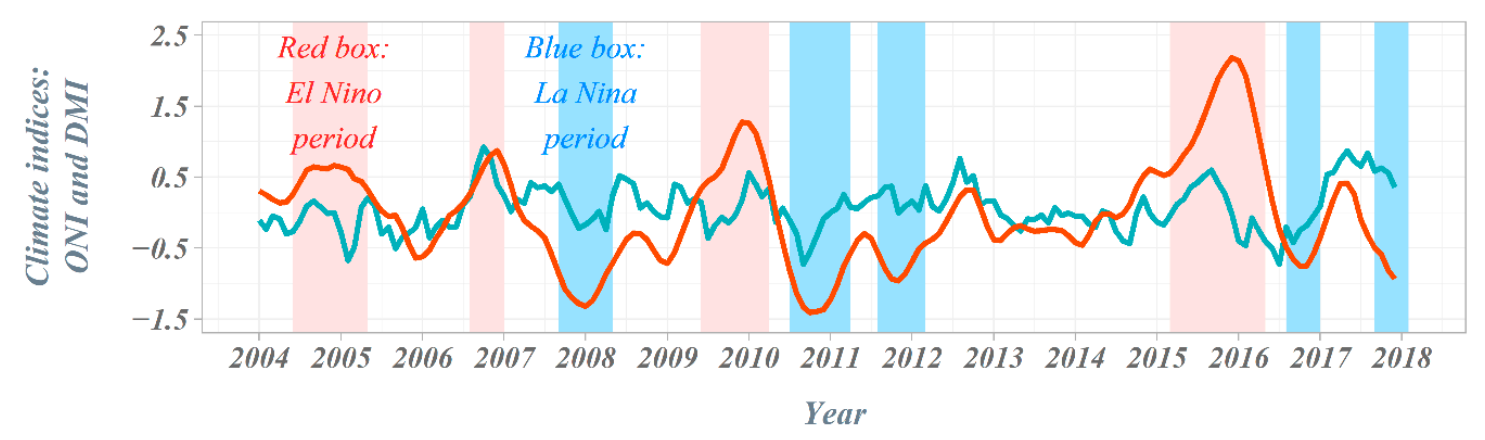

- DMI - ONI

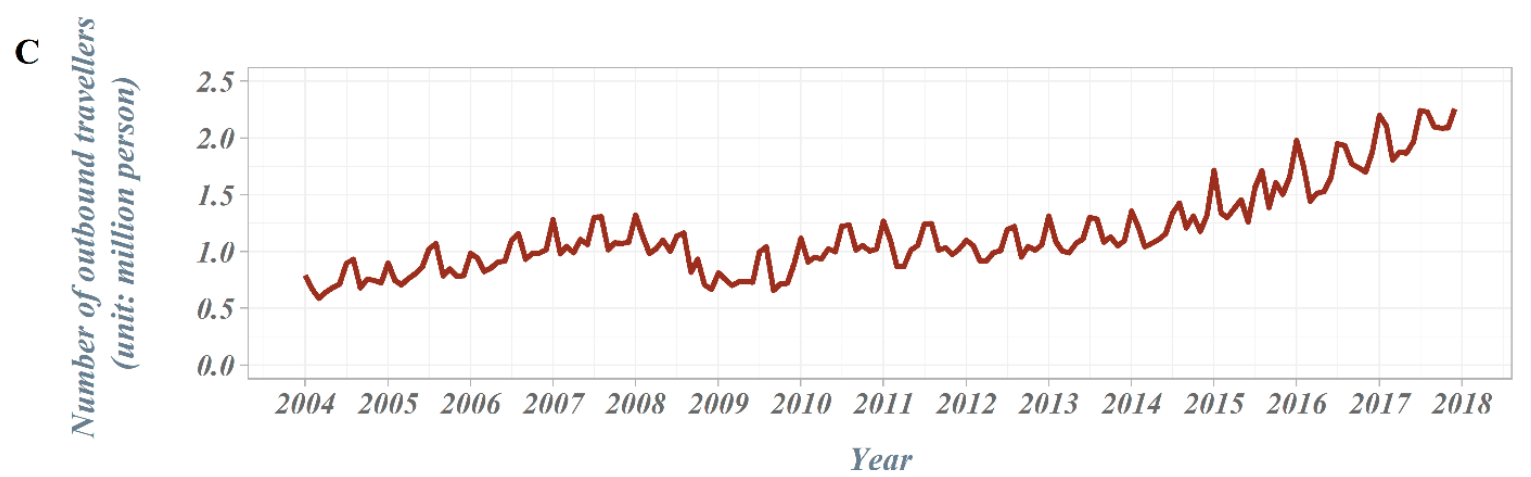

Figure 2. Time trends in the Republic of Korea, 2004-2017. (A) Number of imported shigellosis cases from South and Southeast Asian countries, 2004-2017; (B) time trends of climate indices: ONI and DMI, 2004-2017; (C) number of outbound travelers in the Republic of Korea, 2004-2017.

The number of outbound travelers in South Korea averaged about 750,000 per month in 2004 but continued to increase, exceeding an average of 1.1 million per month in 2007. In 2008-2009, the number of outbound travelers decreased due to the global economic crisis but has steadily increased since then, surpassing an average of 2 million per month in 2017. In the scatter plot between the ONI (DMI) and the number of imported shigellosis cases at lag 0 month from South and Southeast Asian countries, the number of cases tended to increase as the ONI decreased. However, we observed no distinct difference in the DMI values (Figure 3). 
A

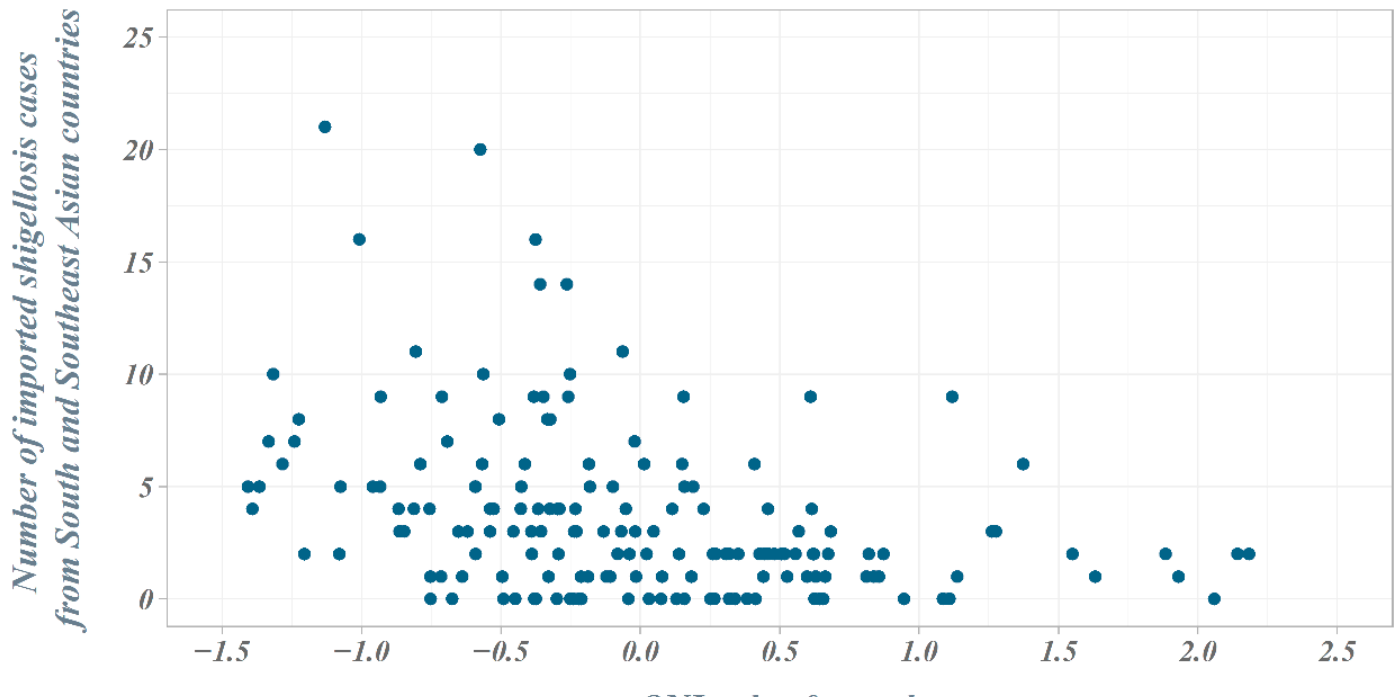

ONI at lag 0 month

B

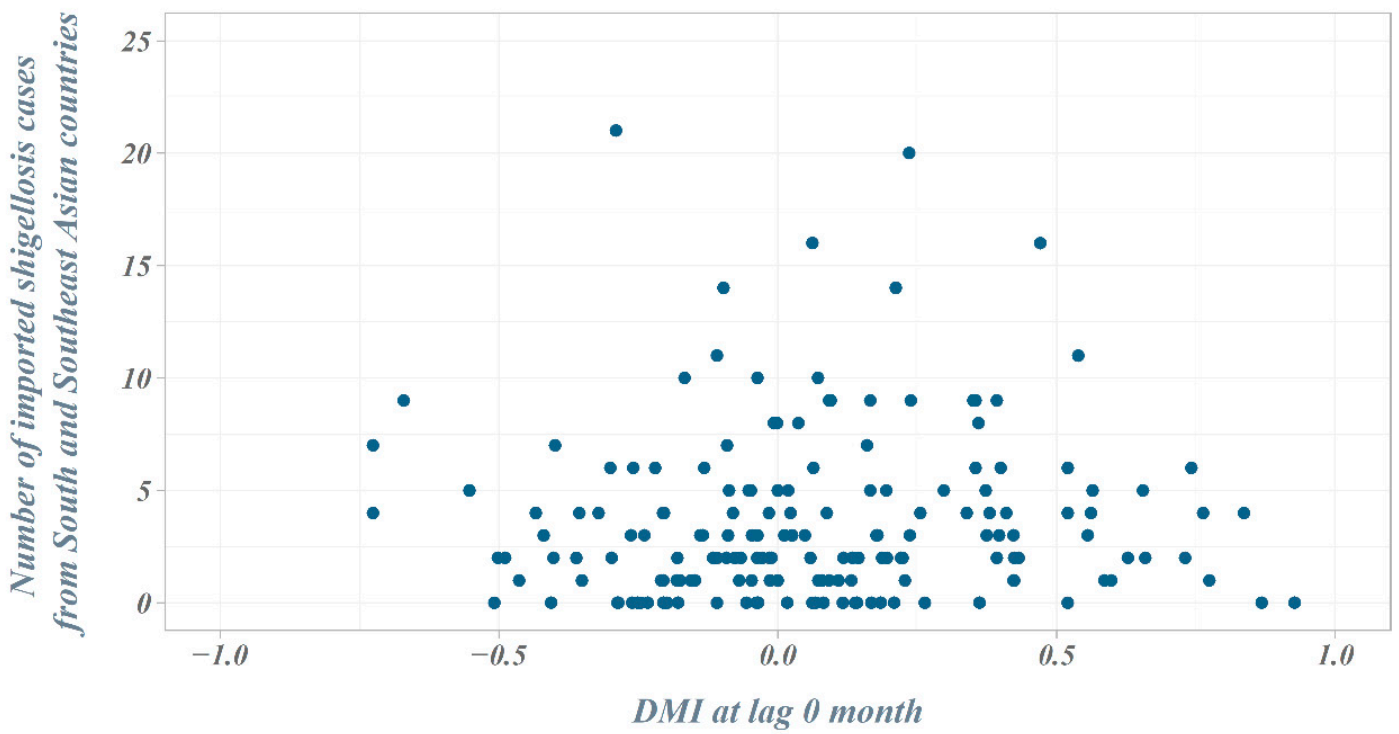

Figure 3. Scatter plot of the number of imported shigellosis cases and climate indices. (A) Scatter plot of the number of imported shigellosis cases and ONI at lag 0 month; (B) scatter plot of the number of imported shigellosis cases and Dipole Mode Index (DMI) at lag 0 month.

As a result of analyzing the relative risk of the ONI and number of shigellosis cases by classifying from zero months to five months, the relative risk associated with shigellosis infection increased as the ONI decreased, until lagged two months (Figure 4). When $0(\mathrm{ONI})$ was used as a reference value, the relative risk at -0.5 (ONI) for lag 0 month was $1.25(1.12-1.40)$ and that at -0.5 (ONI) for lag 1, 2, and 3 months was 1.17 (1.08-1.27), 1.09 (1.03-1.16), and 1.02 (0.97-1.08), respectively. In the five-month cumulative association, the relative risk was $1.38(1.01-1.89)$ at $-0.5(\mathrm{ONI}), 2.57(1.46-4.53)$ at $-1.0(\mathrm{ONI})$, and 3.46 (1.64-7.33) at -1.2 (ONI) (Figure 5). The relative risk increased as the five-month cumulative was stronger (decreased). The relative risk increased significantly at index values below -0.5 (ONI), however, there was no significant change observed at index values above $-0.5(\mathrm{ONI})$. 


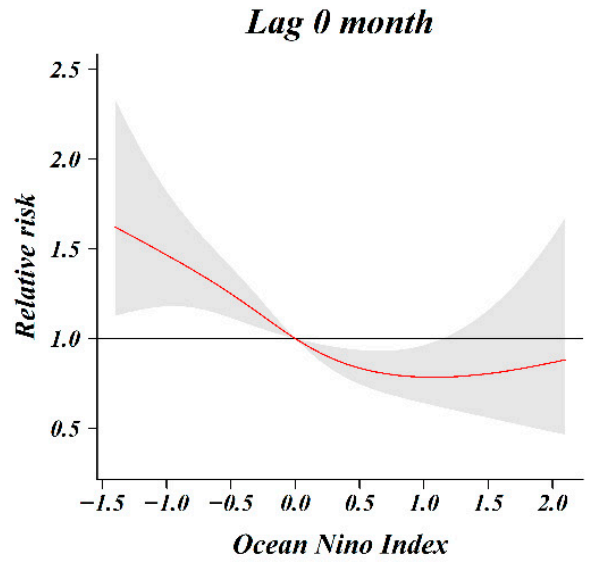

Lag 3 month

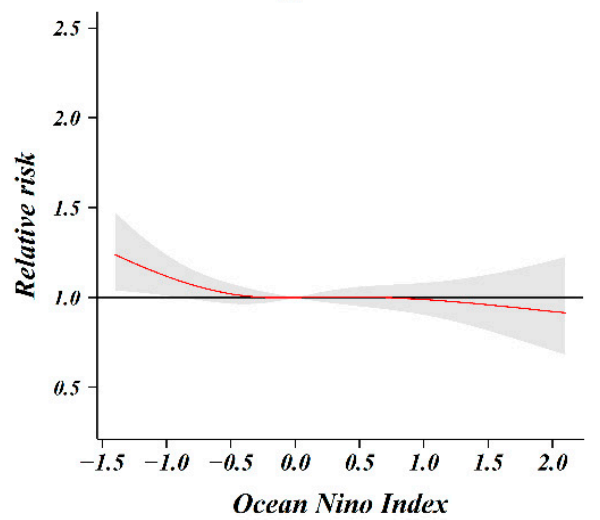

Lag 1 month

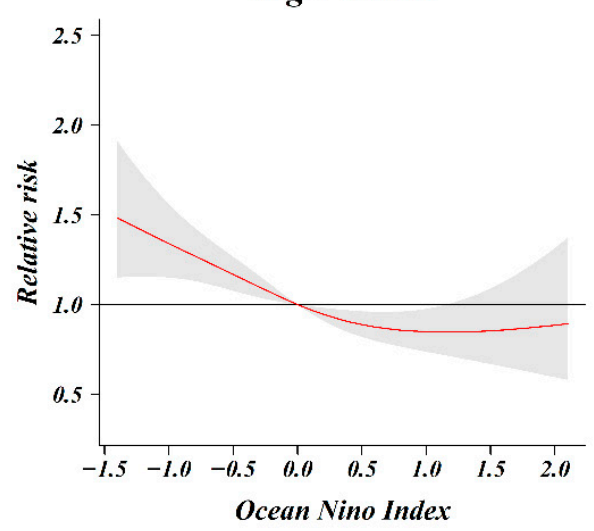

Lag 4 month

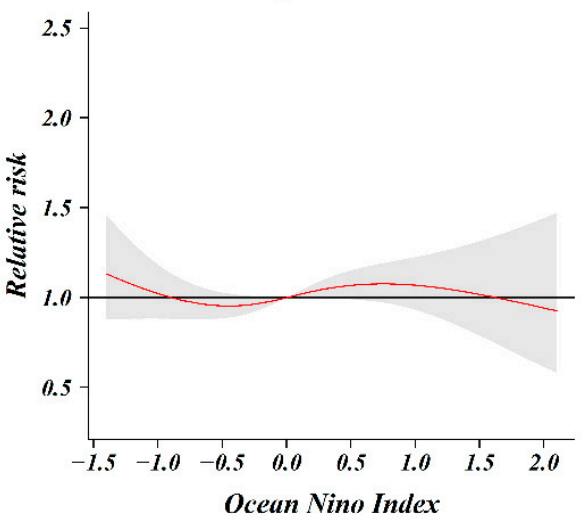

Lag 2 month

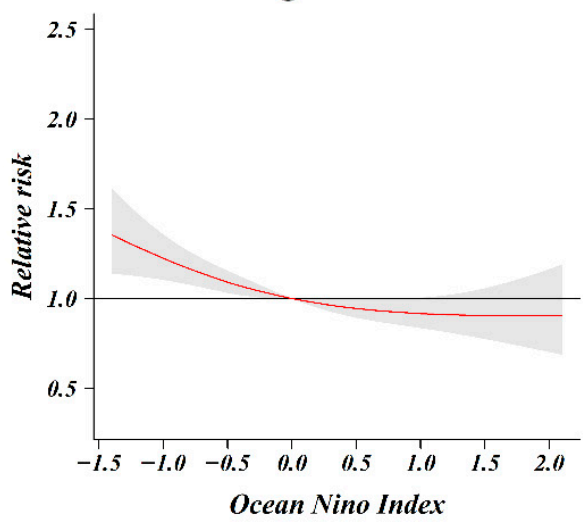

Lag 5 month

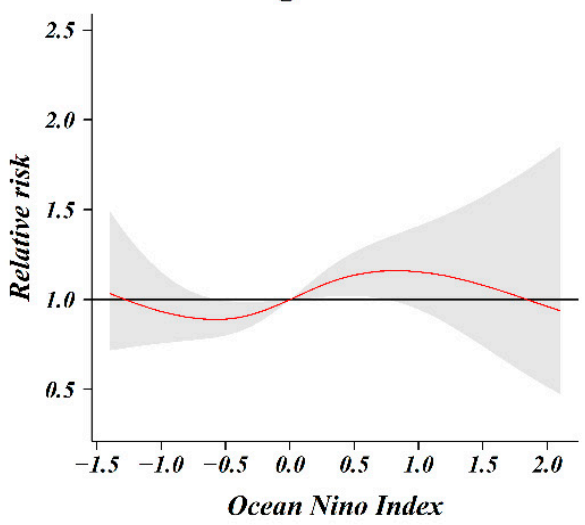

Figure 4. Relative risk according to the lag month of Oceanic Niño Index (ONI).

\section{Overall cumulative association}

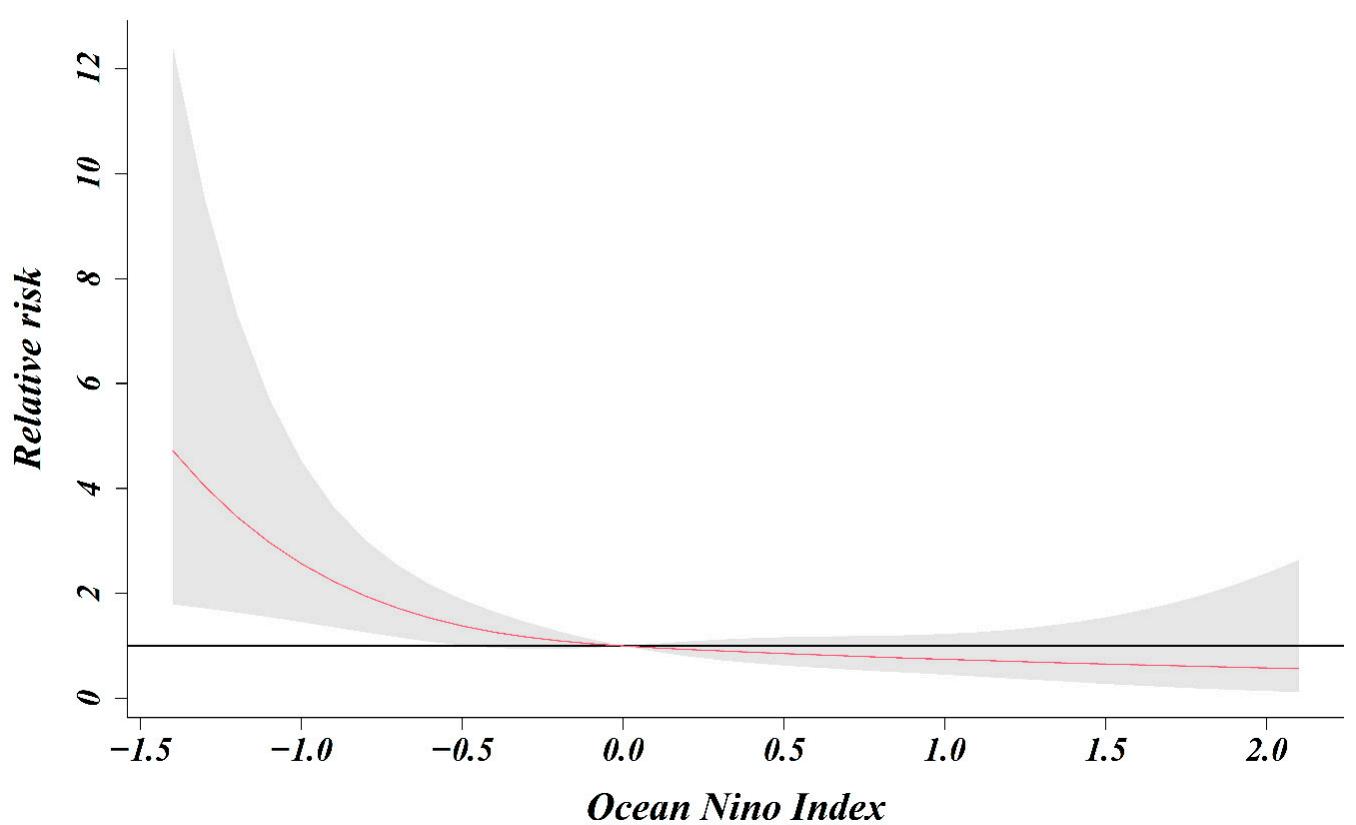

Figure 5. Overall cumulative association (relative risk and ONI). 


\section{Discussion}

We reported that the risk of infection with shigellosis in South Korean travelers returning from South and Southeast Asian countries is influenced by the ONI, a large-scale oceanic index. The risk of this infection was non-linear and markedly increased in the La Niña situation, where the overall cumulative ONI level was less than -0.5 for a period of 5 months. El Niño (La Niña) is based on a three-month moving average of the deviation in sea surface temperatures in the monitoring area (Nino 3.4 region) for El Niño (La Niña). The first month of the period when the ONI of $0.5^{\circ} \mathrm{C}$ or higher lasts more than five months is considered the starting point for El Niño. Additionally, the first month of the period when the ONI of $0.5^{\circ} \mathrm{C}$ or lower lasts more than five months is considered the starting point for La Niña. Based on this definition, our study analyzed the overall cumulative association from the present to the last five months. The influence of meteorological factors on the incidence of shigellosis has a lagged effect, and it is known that a time lag of about 0-2 months considering the survival and incubation period of the pathogen. In our study, the time lag for ONI was classified from zero months to five months. At -0.5 (ONI), the relative risk associated with shigellosis infection was significant from lag zero months to lag two months. As the time lag was shortened, the relative risk increased. The relative risk is highest as $1.25(1.12-1.40)$ at -0.5 (ONI) for lag 0 months. These results can be inferred by reflecting the temporal characteristics that the pathogen Shigella can survive in water for about four weeks, and the incubation period of shigellosis is within one week. Besides, the lagged effect on the increase in shigellosis cases increased by extreme weather events (flood, typhoon) did not exceed one week [8].

ENSO and IOD are climate fluctuations in the Pacific and Atlantic Oceans but are known as important indicators of events that can affect climate globally through teleconnection of the atmosphere and oceans. While fluctuations in the ENSO are relatively influential in the context of global climate fluctuations, the IOD is known to account for approximately $12 \%$ of Indian Ocean sea surface temperature fluctuations, which mainly affect countries adjacent to the Indian Ocean $[20,21]$. Variation in the ENSO and IOD can cause severe flooding and droughts around the world through atmospheric remote connections [7,22]. In particular, South and Southeast Asian regions, which are located in areas impacted by fluctuations in both the ENSO and IOD, are greatly affected by the climate. El Niño and La Niña events occurring during irregular fluctuations in the ENSO also have an impact on public health-associations between hazards such as droughts and flooding, and the incidences of vector-borne diseases (dengue fever and malaria) and diarrheal diseases (cholera) have been reported [23,24]. As heavy rain is generally associated with an increased incidence of intestinal pathogens as a result of contamination of the water supply, the incidence of diarrheal disease usually peaks in the rainy season in tropical regions. In Botswana, Southern Africa, an association between flooding due to the lagged 0-5 months of La Niña's condition and diarrhoea in children under 5 years of age has been reported [25]. In the central region of Vietnam, the incidence of shigellosis has been reported to increase in the local rainy season [26]. In low- and middle-income countries, an increase in precipitation can increase the risk of shigellosis infection by water contaminated through overflowing sewage, runoff human or animal feces from the surface, or the re-suspension of sediment [8]. In this way, an increase in overall rainfall due to La Niña in the Western Pacific region can lead to contamination of drinking water in low- and middle-income countries where infrastructure is relatively poor. Existing studies on the relationship between shigellosis and climate indices have been limited in examining the impact of the ENSO directly, as many studies have been conducted in countries not located in low-latitude regions, such as China [14]. However, in these countries, it is difficult to obtain qualified data due to the limitations in diagnostic testing and infectious disease reporting system. Therefore, outbound travelers in developed countries who visit South and Southeast Asia play the role of geo-sentinel surveillance in low-latitude regions, which highlights their value in providing high-quality sampling data in this regard [27-29]. This is because travelers of northern countries with well-established infectious disease reporting 
systems, who travel and return from Southeast Asia and South Asia can be work as a random sampling of residents of the regions, a proxy of a sentinel surveillance across the region [30].

As overall water safety and hygiene levels improved in South Korea, the number of domestic cases with shigellosis decreased. However, with the increase in the number of overseas travelers, the proportion of imported cases among the total number of cases of shigellosis continued to increase. The absolute number of imported shigellosis cases changes every year due to fluctuating climate indices; the largest number of imported shigellosis cases reported in 2010-2011 was associated with the occurrence of the strongest La Niña at that time during the study period. Of the countries visited by South Korean travelers, Thailand was the most visited country among the Southeast Asian countries, followed by the Philippines, Vietnam, and Singapore (Table S2). However, the reported number of imported shigellosis cases was highest in Cambodia, followed by the Philippines, and Vietnam. The level of water safety, sanitation, and the prevalence of water-borne and food-borne diseases all seem to affect the risk of infection at the national level [31]. In addition, it is already known that when El Niño/La Niña occurs, drought/flood frequently occurs in Southeast Asia and South Asia region. However, in small regions or individual countries, geographic differences may cause weather events that differ from the global climatic phenomenon. Therefore, when the fluctuation in the number of imported shigellosis cases expanded from the single country level to the South and Southeast Asian regions, the relationship with the climate indices and imported shigellosis cases became more apparent. According to data on international tourist destinations from the World Tourism Organization, the number of travelers who visited South and Southeast Asian countries continued to increase from 54 million in 2004 to 148 million in 2017 [32]. As the number of international travelers visiting the region increases rapidly, it is likely that the number of international travelers with shigellosis infections will continue to increase in the future. Therefore, if we can gauge the risk of shigellosis infection due to changes in climate indices in advance, it may help travelers reduce their risk of disease by practicing better personal hygiene and paying attention to their food intake. The number of cases with shigellosis who returned to South Korea after traveling to South and Southeast Asia had a negative association with the monthly ONI. A similar relationship between imported shigellosis cases and ONI will likely be observed if outbound travelers from America and Europe who have visited South and Southeast Asian countries are considered instead. As prediction models of the monthly ONI and DMI have already been developed, it is possible to build a model that predicts the number of cases with shigellosis in South and Southeast Asia in the future.

This study has some limitations. In this study, data reported to the legal infectious disease surveillance system were used for cases of shigellosis infection among South Koreans who entered domestic after a short overseas trip. However, if a tourist infected with shigellosis improves before returning home and does not visit a medical institution in Korea, or if he/she continues to travel after receiving treatment at the local abroad after being infected with shigellosis, data may be omitted and under-reported. The incidence of diarrheal diseases in tropical countries can increase during drought and flood periods. However, there must be an ongoing surveillance system in tropical countries to evaluate the correlation between the incidence of shigellosis and our study's findings in each country. We could not obtain reliable shigellosis surveillance data in each country, which is another limitation of our study. As this study was conducted on South Korean individuals diagnosed with shigellosis after visiting South and Southeast Asian countries, we adjusted the total number of overseas travelers. However, we did not consider regional meteorological factors according to the local area visited. Diarrheal disease is affected not only by meteorological factors, but also by personal hygiene and infrastructural socio-economic factors such as water safety and sanitation. If the spatial resolution is further narrowed to a local area or a single nation, the results may not be the same as those of our study. However, this study attempted to explain the relationship between climate indices in a tropical region 
and the occurrence of shigellosis. In this study, we aimed to assess the impact of the overall cumulative association of climate indices on the incidence of shigellosis in a widespread area such as South and Southeast Asian regions, rather than in a local region with specific meteorological changes.

\section{Conclusions}

The incidence of shigellosis in travelers returning from trips to each Southeast Asian country represents the status of the shigellosis outbreak in each region. However, it is difficult to obtain the incidence data of shigellosis by tourist destinations. To solve these problems, we analyzed the relationship between the ONI and the DMI and the relative risk of shigellosis for overseas travelers. As a result, we have confirmed that the risk of imported shigellosis infection in outbound travelers increases as ONI decreases. Our results suggest that the decreasing trend of ONI, which increases the probability of La Niña occurring, is related to the increased incidence of shigellosis in these South and Southeast Asian countries. It is predicted that extreme rainfall frequency will increase in the future due to climate change. Still, it is difficult to project in advance how the amplitude and spatial pattern of climatic events such as El Niño and La Niña will occur in the distant future. However, the number of international tourist arrivals in South and Southeast Asian countries is increasing rapidly every year. Therefore, it can be expected that shigellosis cases will increase significantly among international tourists visiting this area during the La Niña period. It is recommended that guidance is required to pay attention to hand hygiene and food consumption to tourists visiting the South and Southeast Asian countries during the La Niña period.

Supplementary Materials: The following are available online at https:/ / www.mdpi.com/1660-460 1/18/1/211/s1, Table S1: Sensitivity analysis results sorted in ascending order of the AIC, Table S2: Number of outbound South Korean travelers distributed by travel destination.

Author Contributions: Conceptualization: J.-H.K.; methodology: J.-H.K. and J.S.; data curation: J.-H.K.; formal analysis: J.-H.K.; funding acquisition: H.-J.K.; writing—original draft preparation: J.-H.K.; writing-review and editing: J.-H.K., H.-K.C., H.-J.K., and J.S. All authors have read and agreed to the published version of the manuscript.

Funding: This research was funded by the Korea Centers for Disease Control and Prevention R\&D (2018-P1404-00 \#).

Institutional Review Board Statement: This study was approved by the institutional review board of Dankook University (IRB No. DKUH 2018-09-011).

Informed Consent Statement: Informed consent was waved based on the Infectious Disease Control and Prevention Act, Act No.17067.

Data Availability Statement: Epidemiologic surveillance data sharing is not applicable to this article. However, basic data are open to the public. Materials are provided in Korean only. This data can be found at [http://www.kdca.go.kr/npt/biz/npp/ist/bass/bassAreaStatsMain.do].

Conflicts of Interest: The authors have no conflict of interest to declare for this study.

\section{References}

1. Kotloff, K.L.; Riddle, M.S.; Platts-Mills, J.A.; Pavlinac, P.; Zaidi, A.K.M. Shigellosis. Lancet 2018, 391, 801-812. [CrossRef]

2. Toro, C.; Arroyo, A.; Sarria, A.; Iglesias, N.; Enriquez, A.; Baquero, M.; de Guevara, C.L. Shigellosis in Subjects with Traveler's Diarrhea Versus Domestically Acquired Diarrhea: Implications for Antimicrobial Therapy and Human Immunodeficiency Virus Surveillance. Am. J. Trop. Med. Hyg. 2015, 93, 491-496. [CrossRef] [PubMed]

3. Okhuysen, P.C. Current concepts in travelers' diarrhea: Epidemiology, antimicrobial resistance and treatment. Curr. Opin. Infect. Dis. 2005, 18, 522-526. [CrossRef] [PubMed]

4. Von Seidlein, L.; Kim, D.R.; Ali, M.; Lee, H.; Wang, X.; Thiem, V.D.; Canh, D.G.; Chaicumpa, W.; Agtini, M.D.; Hossain, A.; et al. A multicentre study of Shigella diarrhoea in six Asian countries: Disease burden, clinical manifestations, and microbiology. PLoS Med. 2006, 3, e353. [CrossRef]

5. Leung, A.K.C.; Leung, A.A.M.; Wong, A.H.C.; Hon, K.L. Travelers' Diarrhea: A Clinical Review. Recent Pat. Inflamm. Allergy Drug Discov. 2019, 13, 38-48. [CrossRef] 
6. Shah, N.; DuPont, H.L.; Ramsey, D.J. Global etiology of travelers' diarrhea: Systematic review from 1973 to the present. Am. J. Trop. Med. Hyg. 2009, 80, 609-614. [CrossRef]

7. Kovats, R.S.; Bouma, M.J.; Hajat, S.; Worrall, E.; Haines, A. El Niño and health. Lancet 2003, 362, 1481-1489. [CrossRef]

8. $\mathrm{Wu}, \mathrm{X}$; Liu, J.; Li, C.; Yin, J. Impact of climate change on dysentery: Scientific evidences, uncertainty, modeling and projections. Sci. Total Environ. 2020, 714, 136702. [CrossRef]

9. Rodo, X.; Pascual, M.; Fuchs, G.; Faruque, A.S. ENSO and cholera: A nonstationary link related to climate change? Proc. Natl. Acad. Sci. USA 2002, 99, 12901-12906. [CrossRef]

10. Martinez, P.P.; Reiner, R.C., Jr.; Cash, B.A.; Rodó, X.; Mondal, M.S.; Roy, M.; Yunus, M.; Faruque, A.S.; Huq, S.; King, A.A. Cholera forecast for Dhaka, Bangladesh, with the 2015-2016 El Nino: Lessons learned. PLoS ONE 2017, 12, e0172355. [CrossRef]

11. Ohtomo, K.; Kobayashi, N.; Sumi, A.; Ohtomo, N. Relationship of cholera incidence to El Nino and solar activity elucidated by time-series analysis. Epidemiol. Infect. 2010, 138, 99-107. [CrossRef] [PubMed]

12. Pascual, M.; Rodo, X.; Ellner, S.P.; Colwell, R.; Bouma, M.J. Cholera dynamics and El Nino-Southern Oscillation. Science 2000, 289, 1766-1769. [CrossRef]

13. Cash, B.A.; Rodo, X.; Emch, M.; Yunus, M.; Faruque, A.S.; Pascual, M. Cholera and shigellosis: Different epidemiology but similar responses to climate variability. PLoS ONE 2014, 9, e107223. [CrossRef]

14. Zhang, Y.; Bi, P.; Wang, G.; Hiller, J.E. El Nino Southern Oscillation (ENSO) and dysentery in Shandong province, China. Environ. Res. 2007, 103, 117-120. [CrossRef]

15. Colston, J.; Paredes Olortegui, M.; Zaitchik, B.; Penataro Yori, P.; Kang, G.; Ahmed, T.; Bessong, P.; Mduma, E.; Bhutta, Z.; Shrestha, P.S.; et al. Pathogen-Specific Impacts of the 2011-2012 La Nina-Associated Floods on Enteric Infections in the MAL-ED Peru Cohort: A Comparative Interrupted Time Series Analysis. Int. J. Environ. Res. Public Health 2020, 17, 487. [CrossRef] [PubMed]

16. Korea Tourism Organization. Statistics of Major Destinations for National Overseas Tourists. Available online: https://kto visitkorea.or.kr/kor/notice / data $/$ statis $/$ profit $/$ board $/$ view.kto $i d=430985 \&$ isNotice $=$ false\&instanceId=294\&rnum $=46$ (accessed on 10 May 2020).

17. Asia-Pacific Economic Cooperation (APEC) Climate Center. Climate Indices. Available online: https://www.apcc21.org/ser/ indic.do?lang=en (accessed on 10 May 2020).

18. Gasparrini, A. Modeling exposure-lag-response associations with distributed lag non-linear models. Stat. Med. 2014, 33, 881-899. [CrossRef] [PubMed]

19. Gasparrini, A. Distributed Lag Linear and Non-Linear Models in R: The Package dlnm. J. Stat. Softw. 2011, 43, 1-20. [CrossRef]

20. Saji, N.H.; Goswami, B.N.; Vinayachandran, P.N.; Yamagata, T. A dipole mode in the tropical Indian Ocean. Nature 1999, 401, 360-363. [CrossRef]

21. McPhaden, M.J.; Zebiak, S.E.; Glantz, M.H. ENSO as an integrating concept in Earth science. Science 2006, 314, 1740-1745. [CrossRef]

22. Hrudya, P.H.; Varikoden, H.; Vishnu, R. A review on the Indian summer monsoon rainfall, variability and its association with ENSO and IOD. Meteorol. Atmos. Phys. 2020. [CrossRef]

23. Banu, S.; Guo, Y.; Hu, W.; Dale, P.; Mackenzie, J.S.; Mengersen, K.; Tong, S. Impacts of El Nino Southern Oscillation and Indian Ocean Dipole on dengue incidence in Bangladesh. Sci. Rep. 2015, 5, 16105. [CrossRef] [PubMed]

24. Hashizume, M.; Chaves, L.F.; Faruque, A.S.; Yunus, M.; Streatfield, K.; Moji, K. A differential effect of Indian Ocean dipole and El Nino on cholera dynamics in Bangladesh. PLoS ONE 2013, 8, e60001. [CrossRef]

25. Heaney, A.K.; Shaman, J.; Alexander, K.A. El Nino-Southern oscillation and under-5 diarrhea in Botswana. Nat. Commun. 2019, 10, 5798. [CrossRef] [PubMed]

26. Lee, H.S.; Ha Hoang, T.T.; Pham-Duc, P.; Lee, M.; Grace, D.; Phung, D.C.; Thuc, V.M.; Nguyen-Viet, H. Seasonal and geographical distribution of bacillary dysentery (shigellosis) and associated climate risk factors in Kon Tam Province in Vietnam from 1999 to 2013. Infect. Dis. Poverty 2017, 6, 113. [CrossRef] [PubMed]

27. Taniguchi, H.; Nakano, T.; Katayama, Y.; Harada, F.; Arai, Y.; Mori, K.; Hirata, K.; Kamiya, K.; Maruyama, H.; Sano, K. Sentinel surveillance for international Shigella by a quarantine station in Japan. Epidemiol. Infect. 2005, 133, 611-615. [CrossRef] [PubMed]

28. Leder, K. Travelers as a sentinel population: Use of sentinel networks to inform pretravel and posttravel evaluation. Curr. Infect. Dis. Rep. 2009, 11, 51-58. [CrossRef] [PubMed]

29. Harvey, K.; Esposito, D.H.; Han, P.; Kozarsky, P.; Freedman, D.O.; Plier, D.A.; Sotir, M.J. Surveillance for travel-related diseaseGeoSentinel Surveillance System, United States, 1997-2011. Morb. Mortal. Wkly. Rep. Surveill. Summ. 2013, 62, 1-23.

30. Fukusumi, M.; Arashiro, T.; Arima, Y.; Matsui, T.; Shimada, T.; Kinoshita, H.; Arashiro, A.; Takasaki, T.; Sunagawa, T.; Oishi, K. Dengue Sentinel Traveler Surveillance: Monthly and Yearly Notification Trends among Japanese Travelers, 2006-2014. PLoS Negl. Trop. Dis. 2016, 19, e0004924. [CrossRef]

31. Wendling, Z.A.; Emerson, J.W.; de Sherbinin, A.; Esty, D.C.; Levy, M.A. 2018 Environmental Performance Index. Available online: https:/ / epi.envirocenter.yale.edu/epi-indicator-report/H2O (accessed on 10 May 2020).

32. United Nations World Tourism Organization. Global and Regional Tourism Performance. Available online: https://www.unwto. org/global-and-regional-tourism-performance (accessed on 10 May 2020). 